for an increase in science places, although the evidence is that some of them will be left empty, or filled by students less able than their contemporaries in other dopartments.

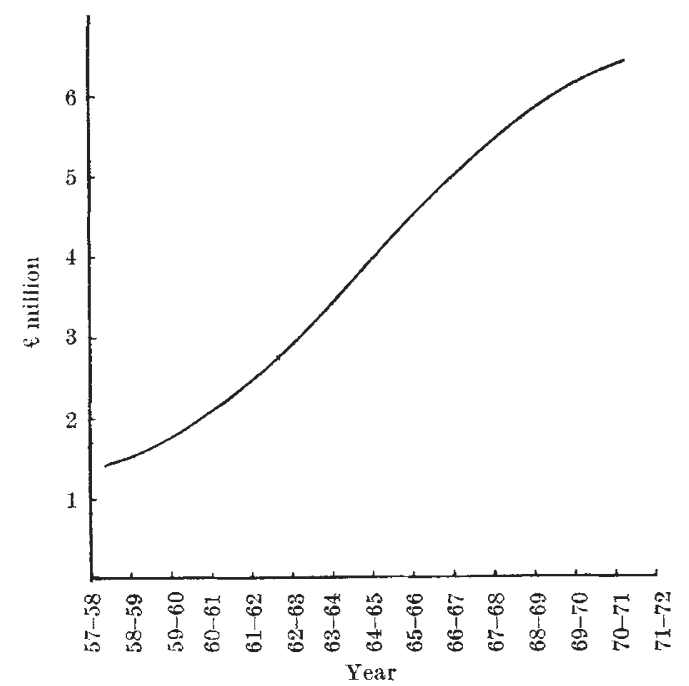

Fig. 2. Support by UGC to Birmingham University, 1957-72.

For the first time, the UGC report includes an interesting survey of the costs of producing graduates in a variety of disciplines. The figures, reproduced below, show how much it costs to produce a graduate in each of the disciplines listed, but do not include the costs of administration, libraries and maintenance of buildings. These costs add up to an additional $£ 260$ per student.

ACADEMIC YEAR, 1966-67

Average Average Staff/ Unit Cost Student Ratio

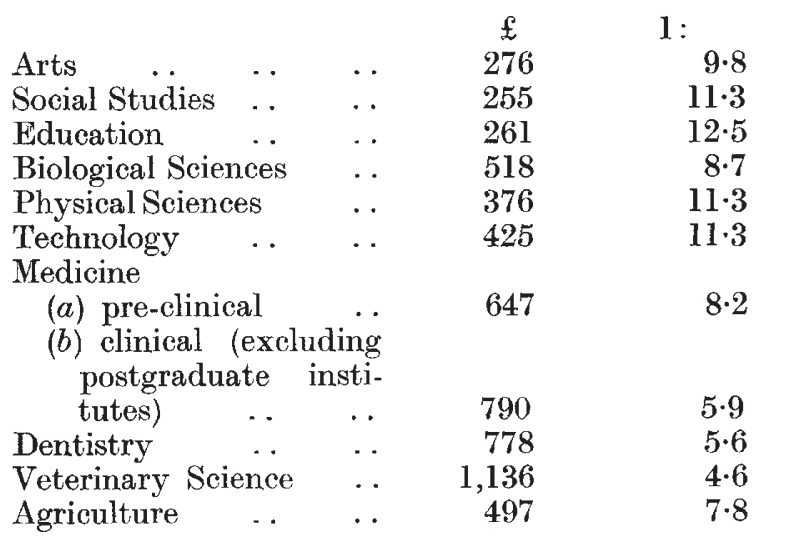

\section{Sonic Booms and Superbooms}

A PRogress report on research into sonic booms has been carried out by a sub-committee of the Committee of the US National Academy of Sciences on SSTSonic Boom (Generation and Propagation of Sonic Boom, National Academy of Sciences. Obtainable in Britain from Universal Subscription Service, Ltd., 4 Footscray Road, London, SE9. 25s.). 'The sub-committee, which was chaired by Dr R. L. Bisplinghoff, professor of aeronautics at MIT, held out no hope for an immediate or dramatic improvement in noise generation.

Progress in supersonic aerodynamics has been such that sonic boom overpressures on the ground can now be accurately predicted to within margins of 10 per cent. But this is only for aircraft flying at constant speed, height and direction and over a quiescent atmosphere. Atmospheric inhomogeneities, such as those caused by temperature variations, wind shears and turbulence, exert a complex effect on the propagation of shock waves which at present is poorly understood. Topographic features and seasonal variations in atmospheric turbulence also exert profound influences on the sonic boom waves that reach the ground, and here again further research is needed.

The phenomenon of "superboom" occurs when shock waves from more than one point of the flight path reach the observer at the same time. This can happen when a supersonic aircraft changes speed or direction, with the result that propagated shock waves are momentarily focused at a single point. Current theory can predict the location of a superboom on the ground but not the size of the pressure wave. The subcommittee is dissatisfied with current investigation into superboom effects, and it considers that more flight and laboratory tests are necessary.

Studies of aircraft design aimed at minimizing sonic boom effects are of prime importance, but the designs so far tested have been relatively conventional. The sub-committee urges that less conventional configuration studies be undertaken in the future. The better radiation characteristics of such fuels as liquid methane or hydrogen hold the possibility of increased propulsion efficiency and possible reduction in sonic boom levels; this is another topic that would merit further attention.

At ground level, little is known about the exact features of the sonic boom which make it undesirable both to animals and to the stability of buildings. The record of the pressure wave as a sonic boom hits the ground, known as its signature, varies both with the type of aircraft and the prevailing conditions. Further research needs to be devoted to determining which parameters of the signature are responsible for damage to human sensibilities on the one hand and to buildings on the other.

It is clear that a large number of problems remain to be solved before the generation and behaviour of sonic booms are thoroughly understood. As far as the Concorde is concerned, the Royal Aircraft Establishment at Farnborough is confident that knowledge of the phenomenon, if not complete, is at least sufficient to allow Concorde flights to proceed. Unforeseen turbulence or topographic effects may perhaps cause prolongation or reverberation of the boom, but they are unlikely to affect the initial sound which is the main cause of annoyance. Unlike military aircraft, which can cause superbooms by abrupt turns or accelerations, the Concorde is expected to produce a superboom only at the period after take-off when its speed becomes supersonic. It is hoped that with suitable planning this superboom can be dumped in the sea.

\section{Industrial Superconductivity}

InTERNATIONAL Research and Development Ltd., a sponsored research organization based in Newcastle upon Tyne, announced this week that it has successfully designed and built an electric motor based on superconducting coils. This has been a dream of engineers since superconductivity-the phenomenon in which metals cooled to very low temperatures lose all 
electrical resistance-was first discovered by the Dutch physicist Kamerlingh Onnes in 1911. But it was not until the development of high-field superconductors and alloys capable of handling very large currents that it became clear that industrial development of superconductivity was worthwhile.

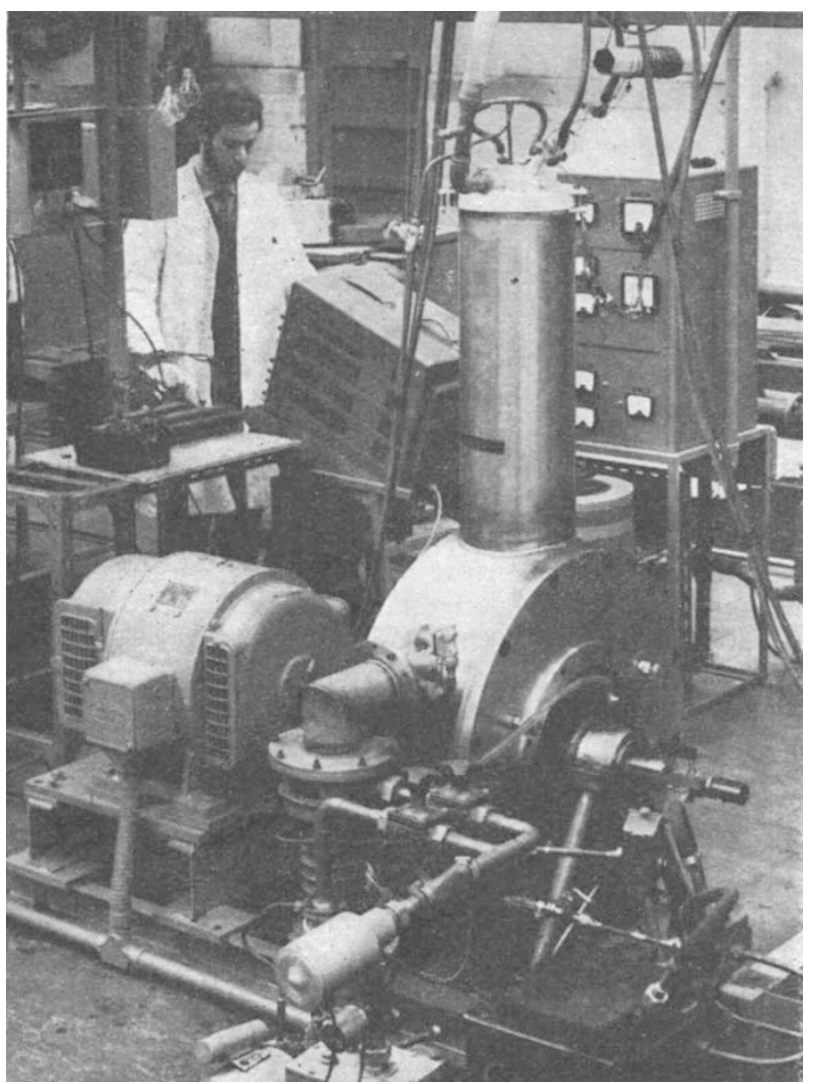

A 50 h.p. superconducting motor developed at International Research and Development Ltd. in Newcastle.

The project at IRD began as a feasibility study for the Ministry of Defence, and showed that a large superconducting motor was possible. Initially a small motor of only 2 h.p. was envisaged, but after some work it was realized that it would be possible to make a much more ambitious motor, producing 50 h.p. and running at 2,000 r.p.m. When this was built, further financial support was sought from the National Research Development Corporation, which appointed a working party to examine the proposal. Although the working party recommended that a 1,000 h.p. motor should first be constructed, NRDC decided to be bold and to go straight to a motor of 3,000 h.p. and 200 r.p.m., the size at which it is estimated superconducting motors will break even on cost with conventional motors. The large motor is to be tested at Fawley power station, by agreement with the Central Electricity Generating Board. The water cooling pumps at Fawley are rated at 3,250 h.p. and 200 r.p.m., designed to be driven by a conventional a.c. motor through reduction gearing. Although the conventional motor runs at 900 r.p.m. to produce the necessary power, the superconducting motor will be able to do it at 200 r.p.m. The stator for the Fawley motor will use a fully stabilized titanium/copper composite super- conductor, cooled by a closed circuit helium refrigerator supplied by British Oxygen Cryoproducts Division. The rotor, which will not be superconducting, will be water cooled.

As well as using superconductivity, the engineers at Newcastle, led by Mr A. D. Appleton, have improved the design of the simple homopolar motor, first devised by Faraday. This type of motor, although very simple in design, has been slow to develop because it calls for a high current and low voltage supply. At IRD a system has been devised which uses a segmented disk - the rotor of the homopolar system-to overcome this difficulty, and $\mathbf{M r}$ Appleton thinks that the new design may have potential uses in electric transport, though not in a superconducting form. Homopolar motors would have the distinct advantage that they could be used to regenerate the batteries while braking the vehicle.

The other advantage of the superconducting motor is a remarkable saving in weight. IRD estimates that with an 8,000 h.p. motor the saving in cost would be $£ 70,000$ ( $£ 150,000$ instead of $£ 220,000$ ) and the superconducting version would weigh only one-ninth as much as the conventional motor. These advantages, IRD believes, will soon make the adoption of superconducting motors inevitable.

\section{Cutting off Europe's Nose}

Technological progress in Europe is being hampered by Britain's exclusion from the EEC. In an address to the Council of Europe on January 29, Mr Anthony Wedgwood Benn, Minister of Technology, reaffirmed the British Government's belief that technical collaboration "within an enlarged common market" is the only way Europe can hope to catch up and keep pace with the United States. Industrial and economic integration will be necessary for this, and Europeanbased international companies must be created if industry is to operate on an adequate scale.

Despite the French veto, which"weakens European economic power in the face of transatlantic pressures", Britain is determined to pursue her policy of collabora. tion with the EEC and is prepared to consult with any country if mutual benefit will result. $\mathrm{Mr}$ Wedgwood Benn said that the decision to devalue the pound, which was taken in the hope of strengthening the economy, has turned Britain "decisively and irrevocably in the direction of Europe". Rationalization of industry within the country has been going on, notably in vehicle manufacturing and the electrical industries, and research projects are being examined for possible areas of collaboration with European countries. Computers, electronics and civil applications of atomic energy are three that have been mentioned already, but there are likely to be many more.

British collaboration is not, however, likely to be limited to Europe. Contact with the United States will be continued, and the technologioal agreements that have been signed with Poland, Hungary, Rumania and the Soviet Union will mean that planning techniques and long-term research will be discussed. $\mathrm{Mr}$ Wedgwood Benn stated his belief that "technological collaboration cannot come to full fruition except within the confines of a single industrial and trading market", and, although Britain's entry into the Common Market has been delayed, it is not too soon for a 